DIGITALCOMMONS

— @WAYNESTATE -
Michigan Journal of Counseling:

Research, Theory and Practice

6-1-2013

\title{
An Evaluation of a Unique Gatekeeper Training for Suicide Prevention of College Students: Demonstrating Effective Partnering within Student Affairs
}

Lisa A. House

Millersville University

Joseph F. Lynch

Millersville University

Mary Bane

Millersville University

Follow this and additional works at: https://digitalcommons.wayne.edu/mijoc

\section{Recommended Citation}

House, L. A., Lynch, J. F., \& Bane, M. (2013). An Evaluation of a Unique Gatekeeper Training for Suicide Prevention of College Students: Demonstrating Effective Partnering within Student Affairs, Michigan Journal of Counseling, 40(1), 27-45. doi:10.22237/ mijoc/1370044980 


\title{
An Evaluation of a Unique Gatekeeper Training for
}

\author{
Suicide Prevention of College Students:
}

Demonstrating Effective Partnering within Student Affairs

Lisa A. House, Joseph F. Lynch, and Mary Bane

Millersville University

For college students, suicide is the second leading cause of death. In this study, we evaluated a gatekeeper training suicide prevention program that emphasizes emotional connectivity with students in crisis and incorporates the collaborative efforts between Housing/Residential Programs and the Counseling Center. Participants consisted of graduate and resident assistants. Very significant gains were found from pre-training to post-training and from pretraining to three-month follow-up in knowledge, skills, and emotional connectivity. Two years of data will be presented.

For college students, suicide is the second leading cause of death resulting in over 1,100 student deaths per year (Center for Disease Control, 2009). Researchers from the American College Health Association (2011), assessed over 105,000 students across the United States, and found that almost $10 \%$ of students seriously contemplated suicide and $1.5 \%$ had made a suicide attempt in the past year. In addition, Hirch and Barton (2011) surveyed 439 college students and found that $46 \%$ of students reported past suicidal ideation, $10 \%$ reported making a past suicide attempt, and $2 \%$ reported that they might attempt suicide in the future (Hirsch \& Barton, 2011). Thus, the development of suicide prevention programs on college campuses is an important and urgent task.

Researchers have indicated that there are numerous risk factors linked to college student suicidal behavior including previous suicide attempts, history of depression or other mental illness, alcohol or drug use, stress, low self-esteem, academic problems, relationship issues, and loneliness (Center for Disease Control, 2009). Some students enter college with pre-existing

\footnotetext{
Dr. Lisa A. House is an assistant professor and licensed psychologist at the Millersville University Counseling Center. She received her B.A. in Psychology from Princeton University in 2002, her M.S. in Clinical Psychology from Rutgers University in 2005 and her Ph.D. in Clinical Psychology from Rutgers University in 2008. Dr. Joseph F. Lynch is a professor and licensed psychologist at the Millersville University Counseling Center. He received his B.A. in Psychology from Villanova University in 1983, his masters in Psychology from Radford University in 1985, and his Ph.D. in Counselor Education from the University of Virginia in 1989. Mary Bane received her B.S. in Psychology from Saint Joseph's University in 2009 and her M.S. in Psychology in 2011 from Millersville University. Mary completed her School Psychology certification in May 2012.
} 
mental health conditions, while others may develop risk factors during their time in college. Garlow et al. (2008) found an association between suicidal ideation, a history of suicidal acts, and depressive symptoms in college students. Specifically, individuals with more severe symptoms of depression were more likely to experience suicidal ideation. An association was also found between suicidal ideation and other internal distress such as anxiety, irritability, and rage (Garlow et al., 2008). College is a major transitional period, which may increase the likelihood for depressive symptoms and exposure to drugs and alcohol which are two major risk factors for suicide (Westefeld et al., 2006).

\section{Gatekeeper Suicide Prevention}

The problem of college student suicide has drawn national attention and encourages college mental health professionals to focus on suicide prevention and intervention. One type of prevention effort for at-risk students is the gatekeeper training method. Gatekeepers have primary contact with people at risk for suicide and identify them by recognizing suicidal risk factors. In essence, gatekeepers open the gate to assistance for people at risk for suicide (Gould \& Kramer, 2001). Gatekeeper training programs aim to enhance recognition and referral by training staff at colleges and universities to help identify students at risk and refer these students to appropriate supportive services or counseling.

Research on gatekeeper training programs for college students is limited. Findings from a recent study on gatekeeper skills of community members after a brief suicide prevention training program, indicated that $10 \%$ of participants met criteria for acceptable gatekeeper skills prior to the training compared to $54 \%$ of participants after training (Cross, Matthieu, Lezine, \& Knox, 2010). According to Aseltine and Demartino (2004), youth who are suicidal may turn to their peers first for help, therefore gatekeeper prevention programs that teach peers how to recognize warning signs of suicide, deal effectively with a student in distress, and make appropriate referrals are important. The benefit of peers helping peers has been supported by research on peer health education programs on college campuses. There is significant support in the literature for the positive effects of peer health educators on college students in regards to making healthy decisions about alcohol and drug use, sex, nutrition and exercise, and mental health issues (Sloane \& Zimmer, 1993; White, Park, Israel, \& Cordero, 2009). Peer health educators have credibility from students and are therefore more likely to facilitate attitude and behavior changes, as well as, be able to understand the experiences of their fellow classmates (Sloane \& Zimmer, 1993).

In a systematic review of gatekeeper training programs, Isaac et al. (2009) concluded that gatekeeper training holds promise as part of a multifaceted strategy to combat suicide. They further concluded that gatekeeper training has been proven to positively affect the skills, attitudes, and knowledge of people who undertake the training in many settings. Two recent studies evaluated one type of gatekeeper training program, Question, Persuade, and Refer (QPR), with college students. Tompkins and Witt (2009) found a positive train- 
ing effect in the domains of appraisal of preparation, efficacy, and intentions to perform in a gatekeeper role. Additionally, Indelicato, Mirsu-Paun, and Griffin (2011) found increased self-ratings in all of the suicide prevention knowledge and skill dimensions over a 3-month period. These results support the benefits of implementation of similar gatekeeper training methods at the university level.

It is important to recognize protective factors against suicidal ideation and behavior when determining the usefulness of a preventative training program. Recent studies support the importance of social support as a protective factor against suicidal ideation and behavior (Park, Cho, \& Moon, 2010; Winfree \& Jiang, 2009; Hirsch \& Barton, 2011). Some gatekeeper training programs utilize this social support element by training peers to be in the role of gatekeepers. Stuart, Waalen, and Stromm (2003) analyzed the usefulness of training peer gatekeepers for suicide risk assessment with high school students. Participants included a total of 65 adolescents between the ages of 13 and 18 years old. Changes in the students' knowledge, skills, and attitudes toward suicide were measured before, immediately after, and three months following the training. Pre-training scores differed significantly from post-training and follow-up, supporting that participants' skill level increased significantly and is similar to that of experts after training than before training. In addition, the difference between the immediate post-training and the follow-up training test was not significant, supporting that the change in skills was maintained over time.

\section{“Campus Connect” Gatekeeper Suicide Prevention Training Program}

The purpose of our study was to evaluate the effectiveness of a gatekeeper suicide prevention training program called "Campus Connect" developed by the Syracuse University Counseling Center (2006). "Campus Connect" is listed on the Suicide Prevention Resource Center/American Foundation for Suicide Prevention Best Practices Registry but there is currently only one empirical study evaluating this program (Pasco, Wallack, Sartin, \& Dayton, 2012). Pasco et al. (2012) found increased improvement in suicide and crisis related knowledge and skills among 65 college student resident advisors who completed the training. In addition, they found that gatekeepers who engaged in the experiential exercises that emphasized communication and relationship skills and taught gatekeepers to emotionally connect with students in crisis had significantly higher crisis response skills than those who only had didactic training (Pasco et al., 2012). On college campuses, individuals who are typically in gatekeeper roles serve as graduate and resident assistants in Residential Life. The Counseling Center collaborated with Housing and Residential Programs to implement "Campus Connect." The goal was to enhance the efficacy of campus suicide prevention. This suicide prevention program emphasizes training graduate and resident assistants as gatekeepers to identify, understand, and relate to the emotional experiences of students in crisis. The goal is to increase relationship building skills, communication skills, and empathic listening skills so that participants can become gatekeepers trained to assist individuals in crisis by helping them feel validated, supported, and understood (Syracuse University, 2006). The key aspects of "Campus Connect" link to the protective factor of so- 
cial support, which research has indicated plays an important role in suicide prevention (Park et al., 2010; Winfree \& Jiang, 2009; Hirsch \& Barton, 2011).

Research in evaluating gatekeeper training for peers is limited. In our study, we sought to address this gap by examining the efficacy of training college students to identify, understand, and relate to other students who may be at risk for suicide. We will present data from two years of gatekeeper training using "Campus Connect."

\section{Participants}

\section{Method}

In 2009, participants included 97 college students from a midsize public university in the Northeast. All students were either graduate or resident assistants, and the majority of the sample were Caucasian (80\%) and female (63\%). Eighty-eight percent of participants ranged between ages 19 and 22, and the majority were college sophomores $(29 \%)$ and juniors (42\%). Of the 97 original participants, 35 participated in the three-month follow-up survey (36\%). In 2010, participants included 87 graduate and resident assistants from the same university, of which $79 \%$ reported to be Caucasian and $53 \%$ were female. Students consisted of sophomores (30\%), juniors $(33 \%)$, seniors $(23 \%)$ and graduate students (14\%). Of the 87 participants, $62 \%$ were participating in the training for the first time and $38 \%$ were participating for the second time. For statistical analyses, participants were divided into two groups: students who were trained the previous year $(\mathrm{N}=32)$ and students who had no previous training $(\mathrm{N}=$ 53). Twenty-nine students participated in the three-month follow-up survey (33\%). See Tables $1 \mathrm{~A}$ and $1 \mathrm{~B}$ for additional information. 


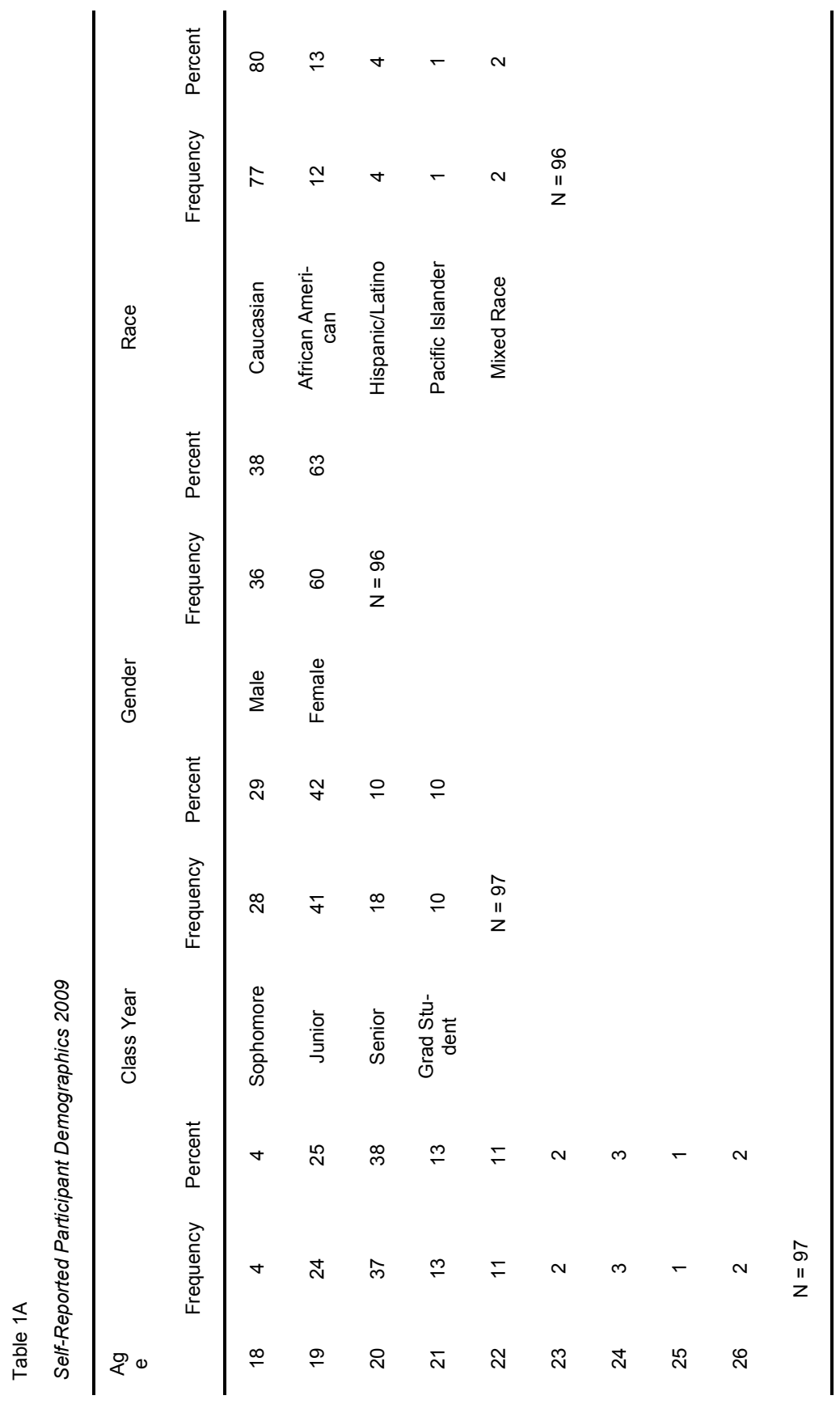




\section{Measures}

The same survey was given both years and consisted of a demographics page that asked for gender, race, age, number of trainings attended, and year in school. In addition, the Suicide Intervention Training Assessment; (SITA) was used. The SITA was created by the originators of the "Campus Connect" prevention program at Syracuse University and measures self-efficacy for specific suicide and crisis response skills. The SITA consists of 14 items that were rated on a Likert scale ranging from 1 ("not at all true") to 10 ("very true"). Sample questions included "I understand the meaning of various suicide terms, "I know how to ask someone if they are thinking about suicide," and "I feel comfortable attempting to emotionally connect with students in crisis." The 14 survey items were divided into three categories. The first category, Knowledge, was related to knowledge and attitudes about suicide and included items 1, 2, 3, 4, 7, and 12. The second category, Skills, comprised items related to the ability to perform gatekeeper behaviors (items 5, 6, 8, 13, and 14). The final category, Emotional Connectivity, was composed of items 9, 10, and 11, and related to the ability to develop a supportive relationship with a student in crisis. The categories of Skills and Emotional Connectivity include aspects of social support, a protective factor identified in suicide prevention. See Table 2 for a complete list of survey items divided by category. 


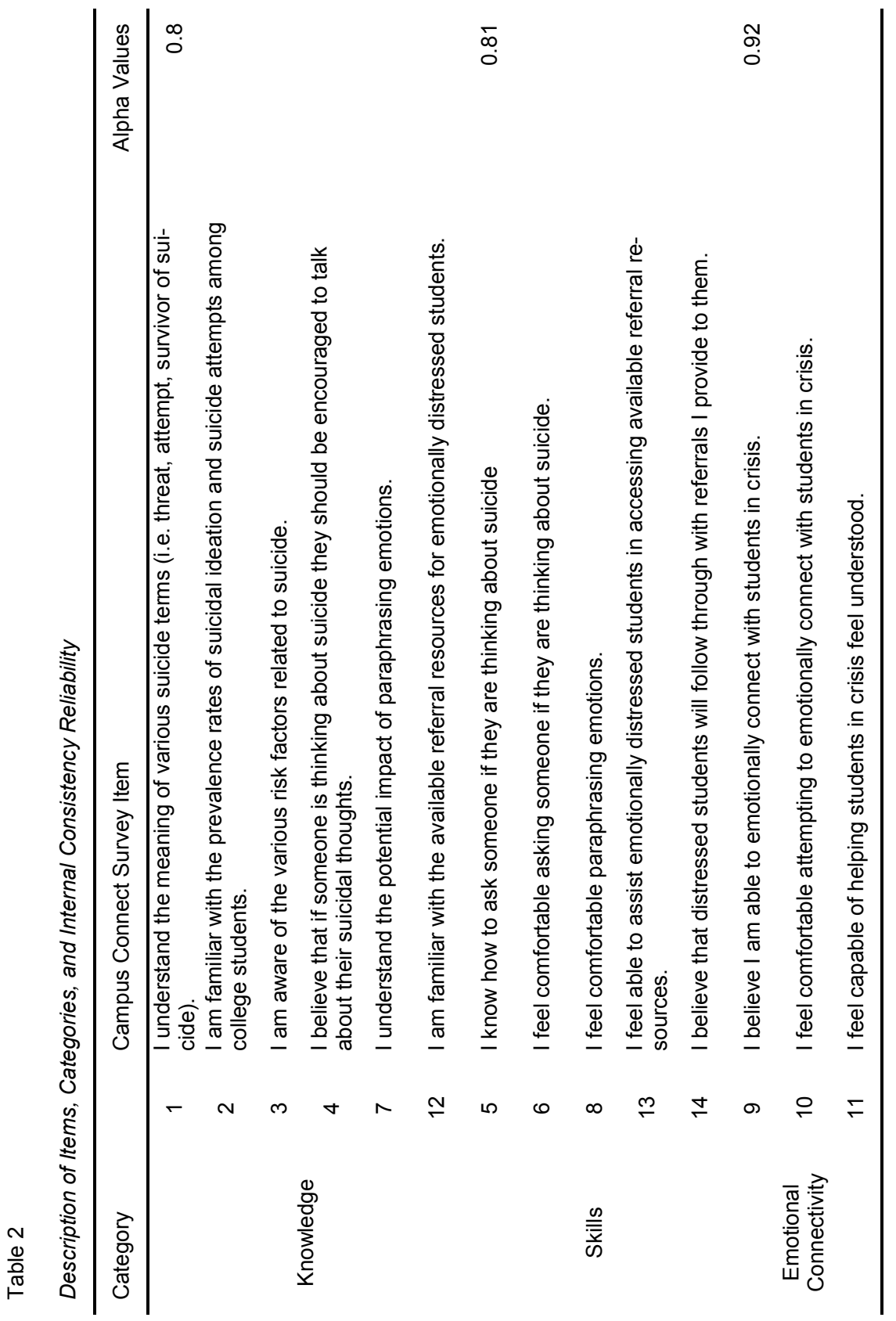




\section{Procedures}

Two Counseling Center faculty members participated in an all-day training on "Campus Connect" with the developers from Syracuse University. These two individuals formally trained the other professional staff within the Department. "Campus Connect" is a manual-based suicide prevention program that is divided into thirteen sections and lasts three hours. Each section has a list of learning objectives, recommended time to complete the activity, and detailed instructions for guiding the training. This program took place in six classrooms, with 16-20 students and one facilitator in each room.

Prior to the training, participants were invited to take part in the study. Informed consent forms were distributed and reviewed with the entire group. Students who agreed to participate completed a pre-training survey and immediately after the training completed a post-training survey. Students who did not wish to participate in the study were instructed to sit quietly and to turn in their blank surveys along with the completed surveys at the end of the training. This was done to avoid any feelings of discomfort for students who did not wish to participate in the study. Participants were asked if they would be willing to take part in a three-month follow-up. If they agreed, they provided their name and mailing address. At the three-month follow-up, participants were mailed the same survey completed at pre and post-training with a postage paid envelope for its return. Students who participated in the follow-up study were entered in a drawing for a $\$ 75$ gift card to the University bookstore. The University Institutional Review Board reviewed and approved our study.

\section{Results}

For both the 2009 and 2010 data, analyses were first completed to examine demographic differences. Significant differences based on academic year (graduate student, senior, junior, or sophomore) were analyzed using $t$ tests by category for pre-training, post-training, and follow-up. Academic year was separated into upperclassmen (graduate students and seniors) and underclassmen (juniors and sophomores) for the purpose of this comparison. For pre -training category 1 , Knowledge, upperclassmen showed significantly higher ratings $(M=6.54, S E=0.26)$ than underclassmen $[(M=5.86, S E=0.17), t(95)$ $=-2.69 ; p<.05]$. Similar results were found in pre-training category 2 , Skills, between upperclassmen $(M=5.35, S E=0.36)$ and underclassmen $[(M=4.56$, $S E=.18), t(95)=-3.19 ; p<.05]$. Comparisons made at post-training showed almost the exact same results as pre-training. In post-training category 1 , Knowledge, upperclassmen showed significantly higher ratings $(M=9.34$, SE $=.10)$ than did underclassmen [( $M=8.95, S E=.08), t(95)=-2.89 ; p<.05]$. In post-training category 2 , Skills, upperclassmen showed significantly higher ratings $(M=8.49, S E-0.18)$ than did underclassmen $[(M=8.00, S E=0.13), t(95)$ $=-2.52 ; p<.05]$.

Comparisons between pre-training, post-training, and follow-up by ethnicity and gender were also conducted using $t$-tests. For ethnicity, participants were divided into two groups: minority and non-minority (Caucasian). No significant differences were found between groups across all three categories 
(Knowledge, Skills, and Emotional Connectivity). Similarly, no significant differences were found between males and females across all three categories.

\section{Effects of Gatekeeper Training Program: 2009 Data}

In order to determine the overall effects of the gatekeeper training program from pre-test to post-test, a series of paired-means $t$-tests were conducted for each individual item and for the three categories (Knowledge, Skills, and Emotional Connectivity). All differences were significant at the $p<.0001$ level, indicating a significant increase in knowledge, skills, and emotional connectivity from pre-test to post-test. Similar statistical procedures were conducted in order to determine differences between pre-test and three-month follow-up. Results indicated a significant increase in knowledge, skills, and emotional connectivity across all items from pre-test to follow-up at the $p<.001$ level or higher. Means, standard deviations, and sample size are summarized in Table 3A.

Paired-sample t-tests were conducted to determine how many gains were retained from post-test to three-month follow-up. Of the 97 original participants, 35 participants (36.1\%) completed the three-month follow-up survey. This survey consisted of the same items presented before (pre-test) and immediately after (post-test) the gatekeeper training. Results indicated decreases in gains from post-test to three-month follow-up, indicating loss of some knowledge and confidence in their ability to perform important gatekeeper behaviors from the training. The level of significance of these decreases varied. Very significant decreases were seen in Knowledge [M(Follow-up - Post) $=$ 0.89; $N=35 ; p<0.01$ ] and Skills [M(Follow-up - Post) $=-.63 ; N=35 ; p<0.01$ ]. Decreases were also seen in Emotional Connectivity [M(Follow-up - Post) = .36; $N=35 ; p=.05]$. Significance levels of difference from post-test to follow-up for each individual item can be seen in Table 3A.

Although there were statistically significant decreases in categories Knowledge and Skills from post-test to three-month follow-up, significant gains in each individual item and category were seen from pre-test to post-test and pre-test to follow-up at the $p<.0001$ level. This indicated that significant gains were maintained over three months. See Table $3 A$ for additional information. 
Table 3A

2009 Data: Participants Average Change by Individual Item and Three Categories Across Pre-test, Post-test, and Follow-up Assessments

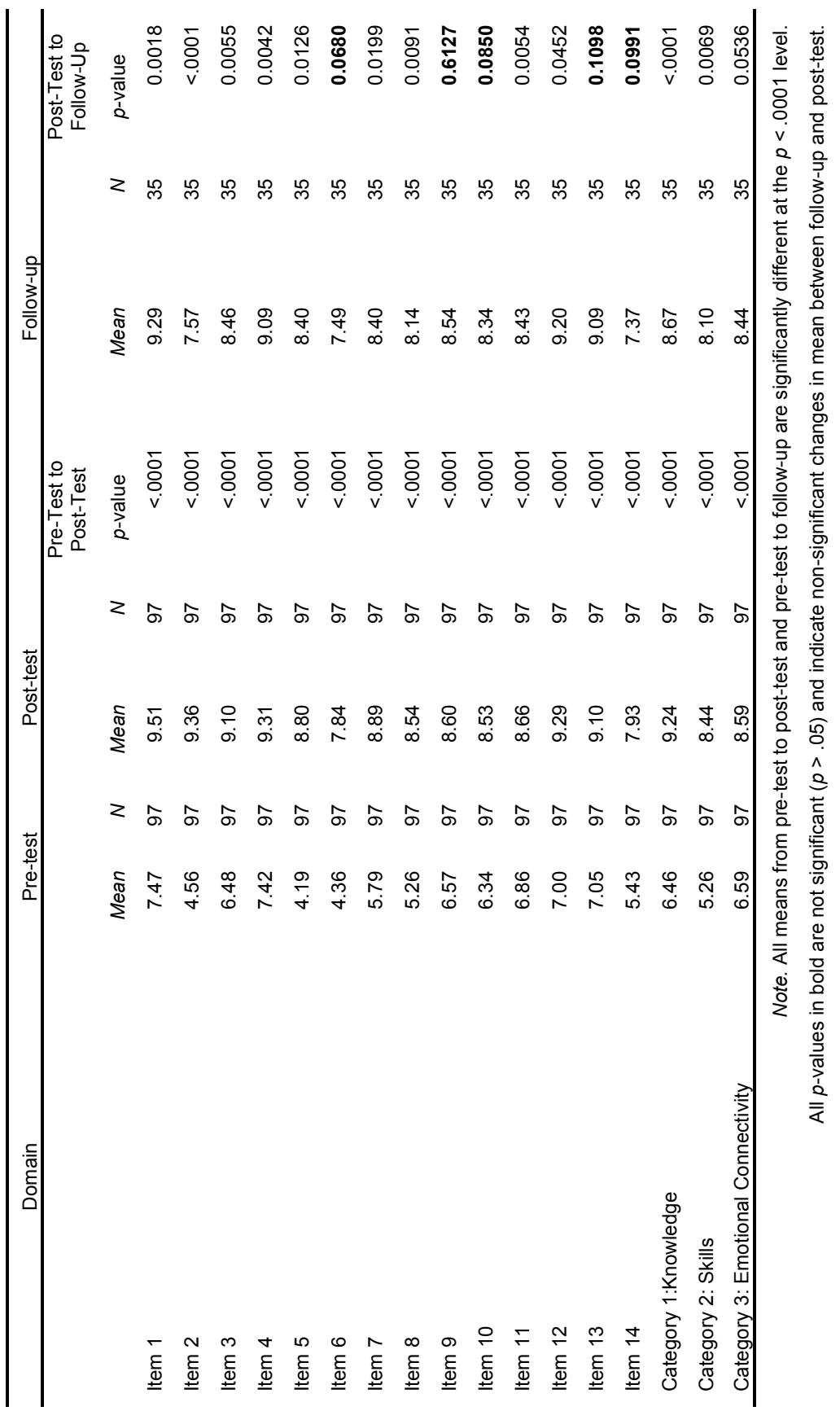




\section{Effects of Gatekeeper Training Program: 2010 Data}

In order to determine the overall effects of the gatekeeper training, participants were divided into two groups: students who were trained the previous year $(N=32)$ and students who had no previous training $(N=53)$. To evaluate the program effects from pre-training to post-training, a series of paired-means $t$ -tests were conducted for each individual item and for the three categories (Knowledge, Skills, and Emotional Connectivity). For both groups, all differences were significant at the $p<.0001$ level, indicating a significant increase in knowledge, skills, and emotional connectivity from pre-test to post-test, for veteran and new graduate and resident assistants. Paired $t$-tests were also conducted to determine differences between pre-test and three-month follow-up. For students with no previous training, results indicated a significant increase in knowledge, skills and emotional connectivity at the $p<.01$ level or higher.

Paired-sample $t$-tests were conducted to determine how many gains were retained from post-test to three-month follow-up. Of the 87 original participants, 29 participants completed the three-month follow-up survey. For graduate and resident assistants who had previous training there were no significant decreases, except for Question 2, indicating no significant loss in knowledge, skills, or emotional connectivity from post-training to three-month follow-up. For graduate and resident assistants taking the training for the first time, results indicated decreases in gains from post-training to three -month follow-up, indicating loss of some knowledge and confidence in their ability to perform important gatekeeper behaviors from the training. Very significant decreases were seen in Knowledge [M(Follow-up - Post) $=-0.75 ; N=29 ; p<0.001]$ and Skills $[M$ (Follow-up - Post) $=-.73 ; N=29 ; p<0.001]$. Decreases in Emotional Connectivity were not significant $[M$ (Follow-up - Post) $=-.45 ; N=29 ; p=.06]$. Please see Tables 3B and 3C for additional information.

Although there were statistically significant decreases in categories Knowledge and Skills from post-test to three-month follow-up, significant gains in each individual question and category were seen from pre-test to post-test and pre-test to follow-up at the $p<.0001$ level for graduate and resident assistants taking the training for the first time. Students who had the training before had some gains but not as significant as the first timers because they started at higher pre-test means due to having had prior training. This indicated that significant gains were maintained over three months compared to the pre-test scores. Please see Tables 3B and $3 \mathrm{C}$ for additional information. 


\begin{tabular}{|c|c|c|c|c|c|c|}
\hline Domain & $\begin{array}{l}\text { Pre- } \\
\text { Test } \\
\text { Mean }\end{array}$ & $\begin{array}{l}\text { Post- } \\
\text { Test } \\
\text { Mean }\end{array}$ & $\begin{array}{l}\text { Follow- } \\
\text { up } \\
\text { Mean }\end{array}$ & $\begin{array}{l}\text { Pre-Test } \\
\text { to Post- } \\
\text { Test } p- \\
\text { value } \\
\mathrm{N}=32\end{array}$ & $\begin{array}{l}\text { Post-Test } \\
\text { to Follow- } \\
\text { up } p \text {-value } \\
N=29\end{array}$ & $\begin{array}{c}\text { Pre-test to } \\
\text { Follow-up } \\
\text { p-value } \\
\mathrm{N}=29\end{array}$ \\
\hline Item 1 & $\begin{array}{c}8.906 \\
3\end{array}$ & $\begin{array}{c}9.718 \\
8\end{array}$ & 9.5833 & $<.0001$ & 0.1911 & 0.096 \\
\hline Item 2 & $\begin{array}{c}7.031 \\
3\end{array}$ & $\begin{array}{c}9.343 \\
8\end{array}$ & 8.25 & $<.0001$ & 0.0183 & 0.096 \\
\hline Item 3 & $\begin{array}{c}8.281 \\
3\end{array}$ & $\begin{array}{c}9.218 \\
8\end{array}$ & 9.4167 & $<.0001$ & 0.3388 & $<.0001$ \\
\hline Item 4 & 8.25 & $\begin{array}{c}9.312 \\
5\end{array}$ & 10 & $<.0001$ & 0.2087 & 0.021 \\
\hline Item 5 & 7.75 & 9.375 & 9.5 & $<.0001$ & 0.7227 & 0.0671 \\
\hline Item 6 & $\begin{array}{c}6.312 \\
5\end{array}$ & $\begin{array}{c}8.562 \\
5\end{array}$ & 8.9167 & $<.0001$ & 0.7602 & 0.095 \\
\hline Item 7 & 8.375 & $\begin{array}{c}9.312 \\
5\end{array}$ & 9.6667 & $<.0001$ & 1 & 0.0105 \\
\hline Item 8 & 7.625 & $\begin{array}{c}8.843 \\
8\end{array}$ & 9.3333 & $<.0001$ & 0.5758 & 0.0197 \\
\hline Item 9 & $\begin{array}{l}7.838 \\
7\end{array}$ & $\begin{array}{c}9.064 \\
5\end{array}$ & 8.75 & $<.0001$ & 0.8837 & 0.0816 \\
\hline Item 10 & $\begin{array}{l}7.687 \\
5\end{array}$ & $\begin{array}{c}9.031 \\
3\end{array}$ & 9.1667 & $<.0001$ & 0.4974 & 0.0372 \\
\hline Item 11 & 8.25 & $\begin{array}{c}9.187 \\
5\end{array}$ & 9.0833 & $<.0001$ & 0.5863 & 0.0674 \\
\hline Item 12 & 8.625 & $\begin{array}{c}9.593 \\
8\end{array}$ & 9.4167 & $<.0001$ & 0.2199 & 0.0527 \\
\hline Item 13 & $\begin{array}{c}8.656 \\
3\end{array}$ & $\begin{array}{c}9.406 \\
3\end{array}$ & 9.5 & $<.0001$ & 0.5863 & 0.0437 \\
\hline Item 14 & $\begin{array}{c}6.843 \\
8\end{array}$ & 8.875 & 8.5 & $<.0001$ & 0.6576 & $<.0001$ \\
\hline $\begin{array}{l}\text { Category } \\
1: \text { Knowledge }\end{array}$ & $\begin{array}{c}8.244 \\
8\end{array}$ & $\begin{array}{c}9.416 \\
7\end{array}$ & 9.3889 & $<.0001$ & 0.2928 & $<.0001$ \\
\hline Category 2: Skills & $\begin{array}{l}7.437 \\
5\end{array}$ & $\begin{array}{c}9.012 \\
5\end{array}$ & 9.15 & $<.0001$ & 0.762 & $<.0001$ \\
\hline $\begin{array}{l}\text { Category 3: } \\
\text { Emotional Con- } \\
\text { nectivity }\end{array}$ & $\begin{array}{c}7.925 \\
4\end{array}$ & $\begin{array}{c}9.094 \\
4\end{array}$ & 9 & $<.0001$ & 0.7047 & 0.0306 \\
\hline
\end{tabular}

Notes. All means from pre-test to post-test are

significantly different at the $p<.0001$ level

All means from pre-test to follow-up had $p$-values ranging

from .09 to $<.0001$

All means, except for question 2 , from post-test to follow-up are not signifi-

cantly different 


\begin{tabular}{|c|c|c|c|c|c|c|}
\hline Domain & $\begin{array}{l}\text { Pre-Test } \\
\text { Mean }\end{array}$ & $\begin{array}{c}\text { Post- } \\
\text { Test } \\
\text { Mean } \\
\end{array}$ & $\begin{array}{c}\text { Follow- } \\
\text { up } \\
\text { Mean }\end{array}$ & $\begin{array}{l}\text { Pre-Test } \\
\text { to Post- } \\
\text { Test } p- \\
\text { value } \\
\mathrm{N}=53\end{array}$ & $\begin{array}{l}\text { Post-Test } \\
\text { to Follow- } \\
\text { up p- } \\
\text { value } \\
\mathrm{N}=29\end{array}$ & $\begin{array}{c}\text { Pre-Test } \\
\text { to Follow } \\
\text {-up p- } \\
\text { value } \\
\mathrm{N}=29\end{array}$ \\
\hline Item 1 & 7.4151 & 9.5000 & 9.0000 & $<.0001$ & $<.0001$ & 0.0200 \\
\hline Item 2 & 4.4151 & 9.0962 & 7.8000 & $<.0001$ & $<.0001$ & $<.0001$ \\
\hline Item 3 & 6.6226 & 8.9231 & 8.8000 & $<.0001$ & 0.1502 & $<.0001$ \\
\hline Item 4 & 7.2264 & 9.4231 & 9.2000 & $<.0001$ & 0.1733 & $<.0001$ \\
\hline Item 5 & 4.2642 & 8.7692 & 9.0667 & $<.0001$ & 0.5667 & $<.0001$ \\
\hline Item 6 & 5.0189 & 7.8942 & 7.5333 & $<.0001$ & $<.0001$ & $<.0001$ \\
\hline Item 7 & 5.7736 & 8.9038 & 8.4000 & $<.0001$ & 0.0342 & $<.0001$ \\
\hline Item 8 & 5.5849 & 8.4038 & 7.8000 & $<.0001$ & $<.0001$ & $<.0001$ \\
\hline Item 9 & 7.1132 & 8.6346 & 8.6000 & $<.0001$ & 0.0335 & 0.0200 \\
\hline Item 10 & 7.4528 & 8.6538 & 8.7333 & $<.0001$ & 0.0824 & $<.0001$ \\
\hline Item 11 & 7.1698 & 8.5192 & 8.8000 & $<.0001$ & 0.5816 & $<.0001$ \\
\hline Item 12 & 5.9811 & 9.0588 & 8.8667 & $<.0001$ & 0.0552 & $<.0001$ \\
\hline Item 13 & 6.1698 & 8.9808 & 9.0000 & $<.0001$ & 0.0552 & $<.0001$ \\
\hline $\begin{array}{l}\text { Item } 14 \\
\text { Category } \\
1: \text { Knowled }\end{array}$ & 5.5472 & 8.1731 & 7.8667 & $<.0001$ & 0.0335 & $<.0001$ \\
\hline ge & 6.2390 & 9.1508 & 8.6778 & $<.0001$ & $<.0001$ & $<.0001$ \\
\hline $\begin{array}{l}\text { Category } \\
\text { 2: Skills } \\
\text { Category } \\
\text { 3: Emo- } \\
\text { tional } \\
\text { Connec- } \\
\text { tivity }\end{array}$ & 5.3170 & 8.4442 & 8.2533 & $<.0001$ & $<.0001$ & $<.0001$ \\
\hline
\end{tabular}

Notes. All means from pre-test to post-test and pre-test to

Means vary from post-test to follow-up. Means that are bold are not signif- 


\section{Evaluation of the Program}

Participant evaluations of the gatekeeper training program were very positive. Data was collected by the Counseling Center and by Housing and Residential Programs using separate evaluation forms. On the Counseling Center's evaluation form, participants were asked to rate the program on a 5-point Likert scale $(1=$ low; $5=$ high). The majority of participants $(97 \%)$ ranked the usefulness of the program as "high" or "very high." When asked how much information was gained during the program, the majority of students (92\%) indicated "high" to "very high" levels of information gained. On the Housing and Residential Programs' evaluation form, participants were asked to comment on how well the gatekeeper program met its goal of: "Educating resident assistants on basic knowledge and referral sources related to suicide and to enhance their communication and relationship building skills so that they can establish a more meaningful and positive relationship with someone who is in crisis." Ninety percent "agreed" or "strongly agreed" that the session's goal was achieved. In addition, $90 \%$ "agreed" or "strongly agreed" that this session or similar sessions should be repeated in future graduate and resident assistant trainings.

In addition to these quantitative evaluations, more qualitative information was gathered to assess how trainees utilized the knowledge and skills they learned from the Campus Connect training in their everyday roles as graduate and resident assistants. This information was gathered through interviews with several of the students who participated in the Campus Connect training the previous summer and then spent the fall and spring semesters working in the residence halls. Participants reported that the Campus Connect training helped them hone their skills to talk with students about struggles they were having and to better identify the level of severity of a particular issue. One student stated, "The training made me more aware of the situations and armed me with the proper arsenal of things to say when dealing with the student. Subtle clues, comments and behaviors are important to learn when identifying and intervening with a student in crisis." Another shared, "This training helped me become a better observer and communicator. It has allowed me to become more aware of potential risks in my hallway."

Other participants reported that the Campus Connect training gave them a sense of confidence and level of comfort when dealing with students in crisis. For example, one student said, "The training certainly made me more comfortable when interviewing the person and trying to determine the extent to which the issue affected them." Another participant shared, "Campus Connect has given me the skills to recognize suicide risks and the confidence to assist students in any way." Furthermore, another student expressed, "In these times, my position as an RA could possibly be the most influential person in that student's life and I feel confident that Campus Connect has helped me to keep my sense of calm and provide the exact services that the student needs." 


\section{Discussion}

This study was conducted to examine the impact of a unique gatekeeper suicide prevention program that emphasized teaching college student resident and graduate assistants to identify, understand, and relate to the emotional experiences of students in crisis. The study also demonstrated the effective collaborative efforts between Housing and Residential Programs and The Counseling Center. Past studies investigating gatekeeper training programs with college students focused on more traditional models of training, which included teaching basic statistics, facts, warning signs, and instruction on making helpful referrals (Tompkins \& Witt, 2009). "Campus Connect" includes these valued topics but also emphasizes enhancing the gatekeeper's ability to establish a more meaningful and positive relationship with the individual in crisis (Syracuse University, 2006).

The main objective of this study was to examine changes in knowledge, skills, and emotional connectivity from pre-training to post-training. Similar to previous studies, this investigation found significant gains from pretraining to post-training in knowledge and self-appraisal of participants' ability to perform important gatekeeper behaviors for both years (Cross et al., 2010; Tompkins \& Witt, 2009; Wyman et al., 2008). This study differed from previous research in that it also assessed gatekeepers' ability to establish supportive relationships with students in crisis. Highly significant gains from both 2009 and 2010 were also found from pre-training to post-training on measures designed to assess participants' ability to emotionally connect with the student in crisis. Connecting with students on an emotional level is an important skill for gatekeepers to learn because students in crisis often feel misunderstood and alone in their distress. These students could benefit from support by gatekeepers to help them feel validated, understood, and supported.

Training peers in a supervisory role to be gatekeepers is beneficial in college environments. These peers already provide a familiar face to students in crisis and any existing relationship with a student may strengthen their ability to connect with students and assist them in getting appropriate help. Collaborating with Housing and Residential Programs and using graduate and resident assistants in the role of gatekeepers increased our access to students who could potentially be in crisis or feeling suicidal.

In 2009, all participants were taking the "Campus Connect" training for the first time. In 2010, approximately two-thirds of the participants were taking the training for the first time and one-third were experiencing the training for the second time. Data from 2009 participants and first time 2010 participants at three-month follow-up showed statistically significant decreases in the categories of knowledge and skills from post-training to three-month follow-up. We believe the decreases in emotional connectivity were not significant from posttraining to follow-up because graduate and resident assistants naturally have opportunities to connect with their students over the course of time. As a result, their appraisal of feeling more confident to connect on an emotional level would be expected to maintain with practice, whereas knowledge learned three months ago, which has not been practiced, would be expected to decrease 
somewhat. Overall, with participants taking the training for the first time, it is important to note there were still significant gains from pre-training to threemonth follow-up in all three domains indicating improved knowledge, appraisal of ability to perform important gatekeeper behaviors, and emotional connectivity lasting at least three-months.

For the individuals taking the 2010 training for the second time, there were no significant decreases in any of the three categories of knowledge, skills, or emotional connectivity from post-training to follow-up. Only one of the fourteen individual items (awareness of suicidal prevalence and attempt rates) showed any significant decrease at all. We might anticipate that individuals who are learning about suicide statistics may forget some of this information three months after the training but what is interesting to note is that those graduate and resident assistants who were taking the training for the second year in a row retained more of the knowledge, skills, and indicators of emotional connectivity even three months following their training. It is also important to note that the 2010 participants taking the training for the second time had higher means on all three tests: pre, post, and follow-up. It was encouraging for us to see that individuals taking the training for the second time not only seemed to retain more knowledge, skills, and emotional connectivity from post to follow-up testing but also consistently scored higher on the pretest than individuals who took the training for the first time in 2010 . These results suggest that there was a benefit for individuals to take the training for a second time. One of the questions that we have received from Housing and Residential Programs is whether graduate and resident assistants should take the training multiple times. Based on these results we have advocated for gatekeepers to take the training for at least two years in a row. Further information from participants taking the training for a third year will need to be reviewed before any additional recommendations can be made.

When we review the data from 2010 participants who took the training for a second time, we noticed that most scores were significantly higher from pre-training to follow-up and all but one of the items showed borderline significant increases. We believe that since the participants' pre-test score means were already higher there was less room for increase and these participants were able to maintain this higher level of retention and confidence through pre, post and follow-up testing.

In addressing the effectiveness of "Campus Connect," our study suggests that students who participated in the training in 2009 and 2010 demonstrated improved knowledge, appraisal of ability to perform important gatekeeper behaviors and emotional connectivity lasting at least three months. Results from participants who took the training previously indicated that there were benefits from taking the training a second time, as evidenced by the increase in their level of retention of knowledge, appraisal of their gatekeeper skills, and perceived ability to connect emotionally with students in crisis had increased. Our study also demonstrated that the successful partnering between the Counseling Center and Housing and Residential Programs facilitated the effective implementation of this unique gatekeeper training. 
There were several limitations to this study. First, our sample included college students from a mid-sized public university in the Northeast, therefore limiting generalizability of results. In addition, specific groups were invited to participate in this study (graduate and resident assistants) creating a sampling bias and there is potential for a test-retest bias among students participating in the program for a second time. Another limitation was that this study did not include a control group. Lastly, our qualitative data was more feedback than true qualitative research. Despite these limitations, this study shows promise for using gatekeeper training for suicide prevention in a college setting.

Future research targeting the effectiveness of gatekeeper training for suicide prevention is warranted. Our study addresses the maintenance of knowledge and self-appraisal of ability to perform important gatekeeper behaviors over time, but it would be important to evaluate those factors more closely. In addition, assessing the referral patterns of gatekeepers is important because it allows researchers to examine the efficiency of gatekeepers' ability to make appropriate referrals for students in need of help. While our study had a valuable longitudinal component looking at maintenance and use of knowledge and skills over time, it is essential for future research to continue to evaluate how often gatekeepers should be trained.

Current studies on gatekeeper training often use self-report data to measure gains within the data collected. Future studies could include data from records kept by Housing and Residential Programs targeting how frequently staff members make referrals to the Counseling Center, Health Services, or other appropriate resources. Additional information could be extracted from incident reports after encouraging graduate and resident assistants to record when they actually ask a student if they are thinking about suicide. Such information could strengthen and support the self-report data that is currently being used to assess these gains.

As indicated above our data suggests that trainees can improve their skills by taking the training a second time. In regards to gatekeepers who would be eligible for taking the training for the third time we are developing a brief check-up or refresher program to facilitate the maintenance of gatekeeper skills and an opportunity to rehearse scenarios to address students in crisis.

In summary, this investigation presents data demonstrating that the implementation of "Campus Connect," a gatekeeper training program for graduate and resident assistants in a college setting, resulted in positive changes of participants' knowledge, self-appraisal of their ability to perform important gatekeeper behaviors, and confidence in their ability to emotionally connect with students in crisis. This unique suicide prevention program benefits from collaboration between the Counseling Center and Housing and Residential Programs, is time and cost effective, and shows promise as an effective strategy to help prevent college student suicide and increase overall student success in college. 


\section{References}

American College Health Association. (2011). National college health assessment, Fall 2011 Reference group executive summary.

Aseltine, R. H. Jr., \& DeMartino, R. (2004). An outcome evaluation of the SOS suicide prevention program. American Journal of Public Health, 94(3), $446-451$.

Center for Disease Control and Prevention. (2009). Injury prevention \& control: Violence prevention: Suicide prevention. Retrieved from http:// www.cdc.gov/violenceprevention/suicide/

Cross, W., Matthieu, M. M., Lezine, D., \& Knox, K. L. (2010). Does a brief suicide prevention program enhance gatekeeper skills? Crisis: The Journal of Crisis Intervention and Suicide Prevention, 31(3), 149-159.

Garlow, S. J., Rosenberg, J., Moore, J. D., Haas, A. P., Koestner, B., Hendin, H., \& Nemeroff, C. B. (2008). Depression, desperation, and suicidal ideation in college students: Results from the American Foundation for Suicide Prevention College Screening Project at Emory University. Depression and Anxiety, 25, 482-488.

Gould, M. S., \& Kramer, R. A. (2001). Youth suicide prevention. Suicide and Life-Threatening Behavior, 31, 6-31.

Hirsch, J. K., \& Barton, A. L. (2011). Positive social support, negative social exchanges, and suicidal behavior in college students. Journal of American College Health, 59(5), 393-398.

Indelicato, N. A., Mirsu-Paun, A., \& Griffin, W. D. (2011). Outcomes of a suicide prevention gatekeeper training on a university campus. Journal of College Student Development, 51(3), 350-361.

Isaac, M., Elias, B., Katz, L.Y., Belik, S. L., Deanc, F. P., Enns, M. W., \& Sareen, J. (2009). Gatekeeper training as a preventative intervention for suicide: A systematic review. The Canadian Journal of Psychiatry, 54 (4), 260-268.

King, K. A., Vidourek, R. A., \& Strader, J. L. (2008). University students' perceived self-efficacy in identifying suicidal warning signs and helping suicidal friends find campus intervention resources. Suicide and LifeThreatening Behavior, 38(5), 608-617.

Park, S. M., Cho, S. I., \& Moon, S. S. (2010). Factors associated with suicidal ideation: Role of emotional and instrumental support. Journal of Psychosomatic Research, 69, 389-397.

Pasco, S., Wallack, C., Sartin, R. M., \& Dayton, R. (2012). The impact of experiential exercises on communication and relational skills in a suicide prevention gatekeeper-training program for college resident advisors. Journal of American College Health, 20(2), 134-140.

Sloane, B. C., \& Zimmer, C. G. (1993). The power of peer health education. Journal of American College Health, 41, 241-245.

Stuart, C., Waalen, J. K., \& Haelstromm, E. (2003). Many helping hearts: An evaluation of peer gatekeeper training in suicide risk assessment.

Death Studies, 27, 321-333.

Syracuse University. (2006). Campus connect: A suicide prevention training for gatekeepers. 
Tompkins, T. L., \& Witt, J. (2009). The short-term effectiveness of a suicide prevention gatekeeper training program in a college setting with residence life advisers. Journal of Primary Prevention, 30, 131-149.

Westefeld, J. S., Button, C., Haley, J. T. Jr., Kettman, J. J., Macconnell, J., Sandil, R., \& Tallman, B. (2006). College student suicide: A call to action. Death Studies, 30, 931-956.

White, S., Park, Y. S., Israel, T., \& Cordero, E. D. (2009). Longitudinal evaluation of peer health education on a college campus: Impact on health behaviors. Journal of American College Health, 57(5), 497-505.

Winfree, L. T., \& Jiang, S. (2010). Youthful suicide and social support: Exploring the social dynamics of suicide-related behavior and attitudes within a national sample of US adolescents. Youth and Juvenile Justice, 8(19), 19-37.

Wyman, P. A., Brown, C. H., Inman, J., Cross, W., Schmeelk-Cone, K., Guo, J., \& Pena, J. B. (2008). Randomized trial of a gatekeeper program for suicide prevention: 1-year impact on school staff. Journal of Consulting and Clinical Psychology, 76, 104-115. 